OPEN ACCESS

Edited by:

Pier Leopoldo Capecchi, University of Siena, Italy

Reviewed by:

Maxim Grymonprez, Ghent University, Belgium

Paari Dominic,

Louisiana State University Health

Shreveport, United States

*Correspondence:

Xiaojuan Wu

xiger6666@126.com

Qiuping Gu

gqp988@163.com

†These authors share first authorship

Specialty section:

This article was submitted to General Cardiovascular Medicine, a section of the journal Frontiers in Cardiovascular Medicine

Received: 12 June 2021

Accepted: 17 August 2021 Published: 08 September 2021

Citation:

Wu X, Hu L, Liu J and Gu Q (2021) Off-Label Underdosing or Overdosing of Non-vitamin K Antagonist Oral Anticoagulants in Patients With Atrial

Fibrillation: A Meta-Analysis Front. Cardiovasc. Med. 8:724301.

doi: 10.3389/fcvm.2021.724301

\section{Off-Label Underdosing or Overdosing of Non-vitamin K Antagonist Oral Anticoagulants in Patients With Atrial Fibrillation: A Meta-Analysis}

\author{
Xiaojuan $\mathrm{Wu}^{1 * t}$, Linyan $\mathrm{Hu}^{2}$, Jinjin $\mathrm{Liu}^{3}$ and Qiuping $\mathrm{Gu}^{1 * t}$ \\ ${ }^{1}$ Department of Gastroenterology, Ganzhou People's Hospital, Ganzhou, China, ${ }^{2}$ Hengshui Health School, Hengshui, China, \\ ${ }^{3}$ Department of Oncology, Ganzhou People's Hospital, Ganzhou, China
}

Background: Several studies have investigated the role of off-label non-vitamin $\mathrm{K}$ antagonist oral anticoagulants (NOACs) in patients with atrial fibrillation (AF). We aimed to compare the effectiveness and safety outcomes between off-label underdose or overdose vs. on-label dose of NOACs in AF patients.

Methods: The PubMed database was systematically searched until August 2021. Observational cohorts were included if they compared the outcomes of off-label underdose or overdose with on-label dose of NOACs in AF patients. The risk ratios (RRs) and $95 \%$ confidence intervals (Cls) were pooled using a fixed-effects model $\left(I^{2} \leq 50 \%\right)$ or a random-effects model $\left(I^{2}>50 \%\right)$.

Results: A total of 15 observational studies were included. Compared with on-label dose of NOACs, off-label underdose of NOACs was associated with increased risks of stroke or systemic embolism $(R R=1.09,95 \% \mathrm{Cl} 1.02-1.16)$, and all-cause death (RR $=1.29,95 \% \mathrm{Cl} 1.10-1.52)$ but not ischemic stroke $(\mathrm{RR}=1.34,95 \% \mathrm{Cl} 0.76-2.36)$, myocardial infarction $(R R=1.08,95 \% \mathrm{Cl} 0.92-1.28)$, major bleeding $(R R=0.97,95 \% \mathrm{Cl}$ $0.89-1.05)$, intracranial hemorrhage $(\mathrm{RR}=1.12,95 \% \mathrm{Cl} 0.90-1.40)$, and gastrointestinal bleeding $(\mathrm{RR}=0.96,95 \% \mathrm{Cl} 0.85-1.07)$, whereas off-label overdose of NOACs was associated with increased risks of SSE $(R R=1.20,95 \% \mathrm{Cl} 1.05-1.36)$, all-cause death $(R R=1.22,95 \% \mathrm{Cl} 1.06-1.39)$, and major bleeding $(\mathrm{RR}=1.33,95 \% \mathrm{Cl} 1.16-1.52)$ but not gastrointestinal bleeding $(\mathrm{RR}=1.18,95 \% \mathrm{Cl} 0.99-1.42)$ and myocardial infarction $(\mathrm{RR}=0.98,95 \% \mathrm{Cl} 0.75-1.30)$.

Conclusion: Compared with on-label dose of NOACs, off-label underdose was associated with increased risks of stroke or systemic embolism and all-cause death, whereas off-label overdose of NOACs was associated with increased risks of stroke or systemic embolism, all-cause death, and major bleeding.

Keywords: atrial fibrillation, anticoagulants, off label, outcomes, meta-analysis 


\section{INTRODUCTION}

Atrial fibrillation (AF) is the most common arrhythmia in clinical practice, affecting millions of people worldwide (1). Appropriate thromboprophylaxis with anticoagulants such as warfarin and non-vitamin $\mathrm{K}$ antagonist oral anticoagulants (NOACs) is an urgent need in general AF patients or patients with other specific conditions (2-4). Since the use of NOACs has improved the benefit-harm profiles for stroke prevention when compared with warfarin, several AF guidelines have regarded NOACs (dabigatran, rivaroxaban, apixaban, or edoxaban) as the first choice drug for stroke prevention in patients with $\operatorname{AF}(1,5)$. A previous study (6) has summarized that the reduced dose of NOACs could be used in several circumstances. In real-world clinical practice, some users of reduced-dose NOACs do not conform to the label- or guideline- recommendations (i.e., offlabel underdose of NOACs) (7). More recently, several studies have explored the effect of off-label underdose or overdose of NOACs in AF patients, but the corresponding findings are not completely consistent. Therefore, this meta-analysis was performed to assess the effectiveness and safety outcomes between off-label underdose or overdose vs. on-label dose of NOACs in patients with AF.

\section{METHODS}

\section{Literature Retrieval}

This meta-analysis was performed according to the Preferred Reporting Items for Reporting Systematic Reviews and Meta-analyses (Supplementary Table 1). This was a metaanalysis of the published studies, and no ethical approval was warranted. The PubMed electronic database was systematically searched until August 2021 for the relevant studies. Supplementary Table 2 shows the detailed search strategies. The reference lists of the included studies were screened to identify the additional publications.

\section{Inclusion and Exclusion Criteria}

Observational cohort studies were included if adult patients with non-valvular $\mathrm{AF}$ received at least off-label underdose or overdose of one NOAC (dabigatran, rivaroxaban, apixaban, or edoxaban). Effectiveness outcomes included stroke or systemic embolism (SSE), ischemic stroke (IS), myocardial infarction (MI), and all-cause death; and safety outcomes included major bleeding, intracranial hemorrhage (ICH), and gastrointestinal (GI) bleeding. The primary effectiveness outcome was SSE, and the primary safety outcome was major bleeding. We defined the reduced-dose NOACs that did not conform to the label- or guideline- recommendations as off-label underdose or overdose of NOACs. The on-label dose of NOACs was regarded as control. We excluded the study type such as reviews, case reports, case series, and meeting abstracts because they had no effect estimates.

\section{Data Extraction and Quality Assessment}

Two authors independently finished the study selection and collected the following data: the first author and publication year, location, design of the study, inclusion period, data source, age and sex, type or dose of NOACs, and definitions of off-label underdose or overdose of NOACs in each included study.

The Newcastle-Ottawa Scale was applied to evaluate the quality of observational studies. This scoring tool had three domains including the selection of cohorts, the comparability of cohorts, and the assessment of the outcome. A study with a Newcastle-Ottawa Scale score of $<6$ points was defined as low quality.

\section{Data Analysis}

The Cochrane Q test and $I^{2}$ statistic were the most commonly reported statistical methods to assess the heterogeneity across the included studies. The results of included studies were expressed as the adjusted risk ratios (RRs) and 95\% confidence intervals (CIs). Propensity score-matched or adjusted RRs and 95\% CIs were abstracted from each included study. We calculated the natural logarithms of RRs and their standard errors of the included studies, which were pooled by a fixed-effects model $\left(I^{2} \leq 50 \%\right)$ or a random-effects model $\left(I^{2}>50 \%\right)$ using an inverse variance method. For the primary effectiveness and safety outcomes, the method of exclusion of one study at a time was applied in the sensitivity analysis. The publication bias was assessed using the funnel plots.

All of the statistical analyses were performed using the Review Manager 5.3 software (the Nordic Cochrane Center, Rigshospitalet, Denmark).

\section{RESULTS}

\section{Study Selection and Patients' Characteristics}

Flowchart of electronic retrievals is presented in Figure 1. A total of 257 records from the PubMed database were identified, and 33 full-text studies were reviewed for more details. Among them, 18 studies were excluded because: (1) eight studies (815) did not report the adjusted RRs; (2) five individual studies have overlapping data (16-20) (3) two studies presented the data of off-label dose (including overdosing and underdosing) vs. on-label dose of NOACs $(21,22)$, and (4) three studies were not observational cohorts (23-25). No additional studies were found in the screenings of the reference lists of the relevant studies. Finally, 15 observational cohort studies were included in this meta-analysis (26-40). The baseline characteristics of the 15 included studies are presented in Table 1. All of the included studies had an acceptable quality with the Newcastle-Ottawa Scale score of $>6$ points.

\section{Effectiveness and Safety of Off-Label Underdose vs. On-Label Dose of NOACs}

As shown in Figures 2, 3, in the pooled analysis, compared with on-label dose of NOACs, off-label underdose of NOACs was associated with increased risks of SSE (RR $=1.09,95 \%$ CI 1.021.16; $\left.P=0.01 ; I^{2}=44 \%\right)$, and all-cause death $(\mathrm{RR}=1.29,95 \%$ CI $\left.1.10-1.52 ; P=0.002 ; I^{2}=71 \%\right)$. There were no significant differences in the rates of IS ( $\mathrm{RR}=1.34,95 \%$ CI $0.76-2.36$; $P=$ $\left.0.32 ; I^{2}=78 \%\right)$, MI $\left(\mathrm{RR}=1.08,95 \% \mathrm{CI} 0.92-1.28 ; P=0.35 ; I^{2}=\right.$ $0 \%)$, major bleeding $\left(\mathrm{RR}=0.97,95 \% \mathrm{CI} 0.89-1.05 ; P=0.43 ; I^{2}\right.$ 


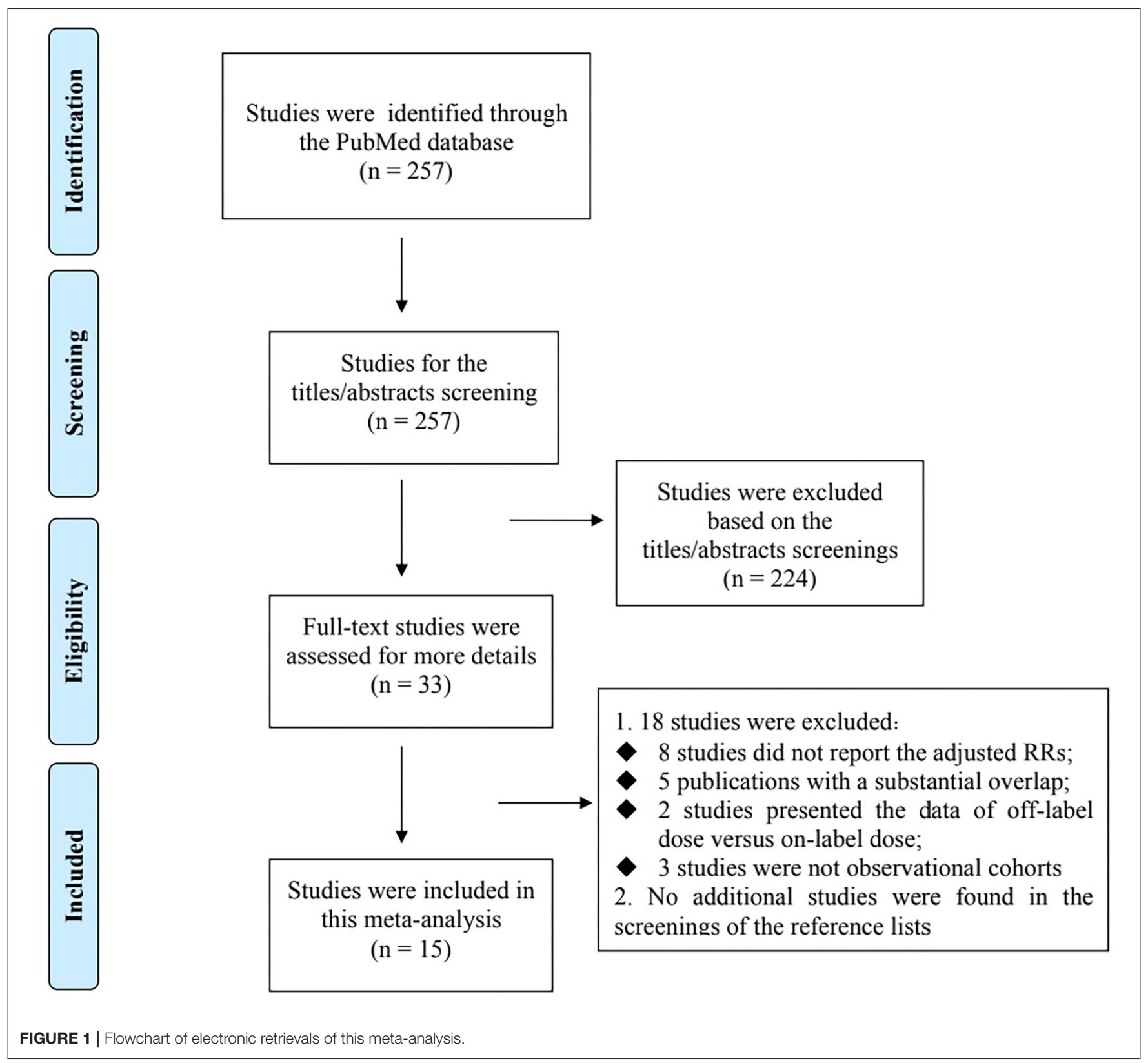

$=29 \%), \mathrm{ICH}\left(\mathrm{RR}=1.12,95 \% \mathrm{CI} 0.90-1.40 ; P=0.30 ; I^{2}=48 \%\right)$, and GI bleeding $\left(\mathrm{RR}=0.96,95 \% \mathrm{CI} 0.85-1.07 ; P=0.44 ; I^{2}=\right.$ $0 \%$ ) between off-label underdose vs. on-label dose of NOACs.

\section{Effectiveness and Safety of Off-Label Overdose vs. On-Label Dose of NOACs}

Based on the pooled results shown in Figures 3, 4, compared with the on-label dose of NOACs, off-label overdose of NOACs was associated with increased risks of SSE ( RR $=1.20$, 95\% CI 1.051.36; $\left.P=0.007 ; I^{2}=0 \%\right)$, all-cause death $(\mathrm{RR}=1.22,95 \% \mathrm{CI}$ $\left.1.06-1.39 ; P=0.004 ; I^{2}=2 \%\right)$, and major bleeding $(\mathrm{RR}=1.33$, 95\% CI 1.16-1.52; $\left.P<0.0001 ; I^{2}=39 \%\right)$, but had similar risks of GI bleeding $\left(\mathrm{RR}=1.18,95 \% \mathrm{CI} 0.99-1.42 ; P=0.07 ; I^{2}=0 \%\right)$ and
MI $\left(\mathrm{RR}=0.98,95 \%\right.$ CI $\left.0.75-1.30 ; P=0.90 ; I^{2}=36 \%\right)$. No pooled data for IS and ICH in this section due to the limited studies.

\section{Sensitivity Analysis and Publication Bias}

For the primary effectiveness and safety outcomes, after we excluded one study at a time, the corresponding results did not change substantially. As shown in Supplementary Figures 1, 2, there were seemingly no obvious publication biases assessed using the funnel plots.

\section{DISCUSSION}

In the present study, our results suggested that compared with the on-label dose of NOACs, the use of off-label underdose 
TABLE 1 | Baseline characteristics of the included studies.

\begin{tabular}{|c|c|c|c|c|c|c|c|}
\hline References & Location & Study period; design & Population source & $\begin{array}{l}\text { Number of } \\
\text { patients }\end{array}$ & $\begin{array}{l}\text { Mean age } \\
(y) / \text { Sex }\end{array}$ & NOACs (type and dosing) & $\begin{array}{l}\text { NOS } \\
\text { tool }\end{array}$ \\
\hline Cheng et al. (34) & Taiwan & 2012-2016; cohort & Taipei Veterans General Hospital & 2,214 & $75.7 /$ both & Underdosing: Rivaroxaban-10 mg & 7 \\
\hline Chen et al. (27) & Taiwan & 2014-2018; cohort & 4 hospitals in southern Taiwan & 1,073 & $75.1 /$ both & Underdosing: apixaban-2.5 mg & 7 \\
\hline Chan et al. (31) & Taiwan & 2011-2018; cohort & Chang Gung Memorial Hospital & 11,275 & 74.2/both & $\begin{array}{l}\text { Underdosing: dabigatran-110 mg; } \\
\text { rivaroxaban-15 or } 10 \mathrm{mg} ; \\
\text { apixaban-2.5 mg; edoxaban-30 mg } \\
\text { Overdosing: dabigatran-150 mg; } \\
\text { rivaroxaban-20 mg; apixaban-5 mg; } \\
\text { edoxaban-60 mg }\end{array}$ & 8 \\
\hline Arbel et al. (37) & Israel & 2011-2017; cohort & Clalit Health Services & 8,245 & 76.5/both & $\begin{array}{l}\text { Dabigatran, rivaroxaban, apixaban; } \\
\text { unknown doses }\end{array}$ & 7 \\
\hline Ikeda et al. (35) & Japan & NR; cohort & XAPASS & 6,159 & 69.2/both & Underdosing: Rivaroxaban-10 mg & 7 \\
\hline Murata et al. (36) & Japan & 2013-2015; cohort & SAKURA AF & 1,115 & 69.0/both & $\begin{array}{l}\text { Underdosing: Dabigatran-110 mg, } \\
\text { rivaroxaban-10 mg, apixaban- } 2.5 \mathrm{mg} \text {, } \\
\text { edoxaban-30 mg }\end{array}$ & 7 \\
\hline Ohno et al. (29) & Japan & 2011-2017; cohort & DIRECT registry & 2,216 & 71.6/both & $\begin{array}{l}\text { Underdosing: dabigatran-110 mg; } \\
\text { rivaroxaban-15 or } 10 \mathrm{mg} ; \\
\text { apixaban-2.5 mg; edoxaban-30 mg } \\
\text { Overdosing: dabigatran-150 mg; } \\
\text { rivaroxaban-20 mg; apixaban-5 mg; } \\
\text { edoxaban-60 mg }\end{array}$ & 8 \\
\hline Yao et al. (38) & United States & 2010-2015; cohort & OptumLabs Data Warehouse & 3,554 & NR/both & $\begin{array}{l}\text { Dabigatran, rivaroxaban, apixaban; } \\
\text { unknown doses }\end{array}$ & 8 \\
\hline Steinberg et al. (40) & United States & 2013-2016; cohort & ORBIT-AF ॥ & 5,738 & 71.0/both & $\begin{array}{l}\text { Underdosing: Dabigatran- } 75 \mathrm{mg} \text {, } \\
\text { rivaroxaban-15 mg, apixaban-2.5 mg } \\
\text { Overdosing: dabigatran-150 mg; } \\
\text { rivaroxaban-20 mg; apixaban-5 mg }\end{array}$ & 8 \\
\hline Briasoulis et al. (33) & United States & 2010-2016; cohort & Medicare beneficiaries & 8,035 & NR/both & $\begin{array}{l}\text { Underdosing: Dabigatran-75 mg; } \\
\text { rivaroxaban-15 mg }\end{array}$ & 7 \\
\hline Ashraf et al. (28) & United States & 2001-2017; cohort & 3 Mayo Clinic sites & 8,125 & 73.3/both & $\begin{array}{l}\text { Underdosing: Dabigatran- } 75 \mathrm{mg} \text {, } \\
\text { rivaroxaban- } 15 \mathrm{mg} \text {, apixaban- } 2.5 \mathrm{mg} \text {, } \\
\text { edoxaban- } 30 \mathrm{mg}\end{array}$ & 8 \\
\hline Lee et al. (39) & Korea & 2012-2013; cohort & $\begin{array}{l}\text { Chonnam National University } \\
\text { Hospital }\end{array}$ & 366 & NR/Both & Underdosing: Dabigatran-110 mg & 7 \\
\hline Yu et al. (30) & Korea & 2013-2016; cohort & $\begin{array}{l}\text { Korean National Health } \\
\text { Insurance Service database }\end{array}$ & 53,649 & 70.5/Both & $\begin{array}{l}\text { Dabigatran, rivaroxaban, apixaban, } \\
\text { edoxaban; unknown doses }\end{array}$ & 8 \\
\hline Camm et al. (32) & $\begin{array}{l}\text { Multicenter, } \\
35 \text { countries }\end{array}$ & 2013-2016; cohort & $\begin{array}{l}\text { Global Anticoagulant Registry in } \\
\text { the FIELD-AF }\end{array}$ & 10,426 & 74.0/both & $\begin{array}{l}\text { Underdosing: Dabigatran-110 mg } \\
\text { (EMA) or } 75 \mathrm{mg}(\mathrm{FDA}) \text {; } \\
\text { rivaroxaban-15 mg; apixaban-2.5 mg; } \\
\text { edoxaban-30 mg }\end{array}$ & 8 \\
\hline Fernandez et al. (26) & Spain & NA; cohort & EMIR & 1,421 & $74.2 /$ both & Underdosing: rivaroxaban-15 mg & 7 \\
\hline
\end{tabular}




\begin{tabular}{|c|c|c|c|c|c|c|c|c|}
\hline \multirow{2}{*}{$\begin{array}{l}\text { Study or Subgroup } \\
\text { 1.1.1 SSE }\end{array}$} & log[Risk Ratio] & SE & Weight & IV, Fixed, $95 \% \mathrm{CI}$ & \multicolumn{4}{|c|}{ IV, Fixed, 95\% Cl } \\
\hline & & & & & & & & \\
\hline Yu-2020 & 0 & 0.048 & $47.4 \%$ & $1.00[0.91,1.10]$ & & & & \\
\hline Yao-2017 & 0.247 & 0.345 & $0.9 \%$ & $1.28[0.65,2.52]$ & & & & \\
\hline Steinberg-2016 & 0.157 & 0.334 & $1.0 \%$ & $1.17[0.61,2.25]$ & & & & \\
\hline Ohno-2020 & -0.507 & 0.592 & $0.3 \%$ & $0.60[0.19,1.92]$ & & & & \\
\hline Murata-2019 & -0.161 & 0.382 & $0.7 \%$ & $0.85[0.40,1.80]$ & & & & \\
\hline Lee-2017 & 0.03 & 0.631 & $0.3 \%$ & $1.03[0.30,3.55]$ & & & & \\
\hline Ikeda-2019 & 0.372 & 0.141 & $5.5 \%$ & $1.45[1.10,1.91]$ & & & 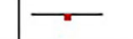 & \\
\hline Chen-2021 & 0.255 & 0.304 & $1.2 \%$ & $1.29[0.71,2.34]$ & & & & \\
\hline Chan-2020 & 0.464 & 0.122 & $7.3 \%$ & $1.59[1.25,2.02]$ & & & 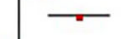 & \\
\hline Camm-2020 & -0.083 & 0.202 & $2.7 \%$ & $0.92[0.62,1.37]$ & & & & \\
\hline Ashraf-2021 & 0.086 & 0.061 & $29.4 \%$ & $1.09[0.97,1.23]$ & & & $f=$ & \\
\hline $\begin{array}{l}\text { Arbel-2019 } \\
\text { Subtotal }(95 \% \mathrm{Cl})\end{array}$ & 0.02 & 0.184 & $\begin{array}{r}3.2 \% \\
100.0 \%\end{array}$ & $\begin{array}{l}1.02[0.71,1.46] \\
1.09[1.02,1.16]\end{array}$ & & & $\downarrow$ & \\
\hline \multicolumn{9}{|c|}{$\begin{array}{l}\text { Heterogeneity: } \mathrm{Chi}^{2}=19.74, \mathrm{df}=11(\mathrm{P}=0.05) ; \mathrm{I}^{2}=44 \% \\
\text { Test for overall effect: } Z=2.49(P=0.01)\end{array}$} \\
\hline \multicolumn{9}{|l|}{ 1.1.2 Major bleeding } \\
\hline Yu-2020 & -0.01 & 0.059 & $54.0 \%$ & $0.99[0.88,1.11]$ & & & & \\
\hline Yao-2017 & 0.058 & 0.202 & $4.6 \%$ & $1.06[0.71,1.57]$ & & & & \\
\hline Steinberg-2016 & -0.223 & 0.22 & $3.9 \%$ & $0.80[0.52,1.23]$ & & & & \\
\hline Ohno-2020 & -0.056 & 0.334 & $1.7 \%$ & $0.95[0.49,1.82]$ & & & & \\
\hline Murata-2019 & -0.747 & 0.448 & $0.9 \%$ & $0.47[0.20,1.14]$ & & & & \\
\hline Lee-2017 & -1.022 & 1.14 & $0.1 \%$ & $0.36[0.04,3.36]$ & & & & \\
\hline Ikeda-2019 & -0.198 & 0.153 & $8.0 \%$ & $0.82[0.61,1.11]$ & & & & \\
\hline Chen-2021 & 0.182 & 0.283 & $2.3 \%$ & $1.20[0.69,2.09]$ & & & & \\
\hline Chan-2020 & -0.223 & 0.238 & $3.3 \%$ & $0.80[0.50,1.28]$ & & & & \\
\hline Camm-2020 & -0.693 & 0.292 & $2.2 \%$ & $0.50[0.28,0.89]$ & & & & \\
\hline $\begin{array}{l}\text { Briasoulis-2020 } \\
\text { Subtotal }(95 \% \mathrm{Cl})\end{array}$ & 0.113 & 0.1 & $\begin{array}{r}18.8 \% \\
100.0 \%\end{array}$ & $\begin{array}{l}1.12[0.92,1.36] \\
0.97[0.89,1.05]\end{array}$ & & & & \\
\hline \multicolumn{9}{|c|}{$\begin{array}{l}\text { Heterogeneity: } \mathrm{Chi}^{2}=14.02, \mathrm{df}=10(P=0.17) ; \mathrm{I}^{2}=29 \% \\
\text { Test for overall effect: } Z=0.78(P=0.43)\end{array}$} \\
\hline \multicolumn{9}{|l|}{ 1.1.3 MI } \\
\hline Yu-2020 & 0.086 & 0.093 & $83.6 \%$ & $1.09[0.91,1.31]$ & & & & \\
\hline Steinberg-2016 & 0.278 & 0.446 & $3.6 \%$ & $1.32[0.55,3.16]$ & & & & \\
\hline Ikeda-2019 & 0.577 & 0.75 & $1.3 \%$ & $1.78[0.41,7.74]$ & & & & \\
\hline $\begin{array}{l}\text { Arbel-2019 } \\
\text { Subtotal }(95 \% \mathrm{Cl})\end{array}$ & -0.083 & 0.251 & $\begin{array}{r}11.5 \% \\
100.0 \%\end{array}$ & $\begin{array}{l}0.92[0.56,1.51] \\
1.08[0.92,1.28]\end{array}$ & & & & \\
\hline \multicolumn{9}{|c|}{$\begin{array}{l}\text { Heterogeneity: } \mathrm{Chi}^{2}=1.06, \mathrm{df}=3(P=0.79) ; I^{2}=0 \% \\
\text { Test for overall effect: } Z=0.94(P=0.35)\end{array}$} \\
\hline \multicolumn{9}{|l|}{$1.1 .4 \mathrm{ICH}$} \\
\hline Yu-2020 & 0.215 & 0.126 & $78.2 \%$ & $1.24[0.97,1.59]$ & & & & \\
\hline Cheng-2019 & -0.478 & 0.337 & $10.9 \%$ & $0.62[0.32,1.20]$ & & & & \\
\hline $\begin{array}{l}\text { Briasoulis-2020 } \\
\text { Subtotal }(95 \% \mathrm{Cl})\end{array}$ & -0.01 & 0.338 & $\begin{array}{r}10.9 \% \\
\mathbf{1 0 0 . 0 \%}\end{array}$ & $\begin{array}{l}0.99[0.51,1.92] \\
1.12[0.90,1.40]\end{array}$ & & & & \\
\hline \multicolumn{9}{|c|}{$\begin{array}{l}\text { Heterogeneity: } \mathrm{Chi}^{2}=3.86, \mathrm{df}=2(P=0.14) ; I^{2}=48 \% \\
\text { Test for overall effect: } Z=1.03(P=0.30)\end{array}$} \\
\hline \multicolumn{9}{|l|}{ 1.1.5 GI bleeding } \\
\hline Yu-2020 & -0.094 & 0.07 & $69.8 \%$ & $0.91[0.79,1.04]$ & & & & \\
\hline Ohno-2020 & 0.029 & 0.443 & $1.7 \%$ & $1.03[0.43,2.45]$ & & & & \\
\hline Lee-2017 & -0.616 & 1.22 & $0.2 \%$ & $0.54[0.05,5.90]$ & & & & \\
\hline $\begin{array}{l}\text { Briasoulis-2020 } \\
\text { Subtotal }(95 \% \mathrm{CI})\end{array}$ & 0.077 & 0.11 & $\begin{array}{r}28.3 \% \\
100.0 \%\end{array}$ & $\begin{array}{l}1.08[0.87,1.34] \\
0.96[0.85,1.07]\end{array}$ & & & & \\
\hline \multicolumn{9}{|c|}{$\begin{array}{l}\text { Heterogeneity: } \text { Chi }^{2}=1.97, \mathrm{df}=3(P=0.58) ; 1^{2}=0 \% \\
\text { Test for overall effect: } Z=0.77(P=0.44)\end{array}$} \\
\hline & & & & & $\begin{array}{ll} & 0.1 \\
\end{array}$ & $\begin{array}{c}0.5 \\
\text { on-label dose }\end{array}$ & $1 \underset{2}{2}$ & $\begin{array}{cc}5 \\
\text { I underdose }\end{array}$ \\
\hline
\end{tabular}

FIGURE 2 | A fixed-effects model for comparing the outcomes between off-label underdose and on-label dose of NOACs in patients with atrial fibrillation. NOACs, non-vitamin K antagonist oral anticoagulants; SSE, stroke or systemic embolism; IS, ischemic stroke; MI, myocardial infarction; ICH, intracranial hemorrhage; GI, gastrointestinal; Cl, confidence interval; SE, standard error; IV, inverse of the variance. 


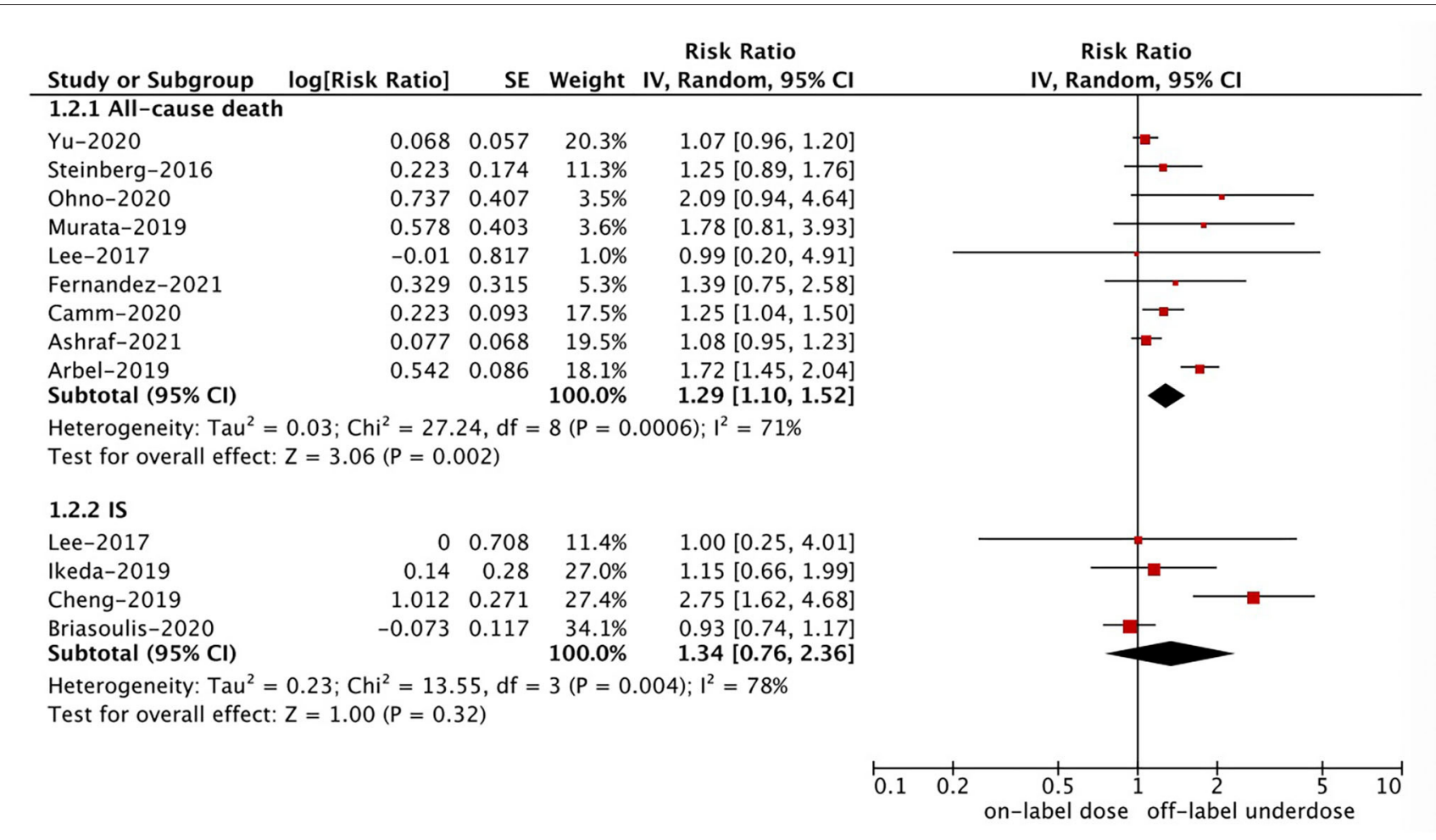

FIGURE 3 | A random-effects model for comparing the outcomes between off-label underdose and on-label dose of NOACs in patients with atrial fibrillation. NOACs, non-vitamin K antagonist oral anticoagulants; IS, ischemic stroke; Cl, confidence interval; SE, standard error; IV, inverse of the variance.

of NOACs was associated with increased risks of SSE and allcause death but not IS, MI, and bleeding outcomes, whereas the use of off-label overdose of NOACs was associated with increased risks of SSE, all-cause death, and major bleeding but not MI and GI bleeding. Our current evidence further support the findings of previous meta-analyses $(41,42)$ by adding the latest studies, suggesting the importance of appropriate NOAC dosing according to the NOAC-dose adjustment criteria.

Despite the greater net clinical benefit of NOACs compared with warfarin among AF patients, there are still many patients who do not receive appropriate oral anticoagulant therapy. Recent observational data have shown that the NOAC dosing that is inconsistent with the label- or guideline-recommendations are becoming a widespread phenomenon $(38,43,44)$. Inappropriate NOAC dosing in routine clinical practice is a serious concern and may be associated with an increase in the risk of adverse events. The reasons why physicians select the underdose of NOACs remain unclear. Patients in real-world settings are often sicker and more fragile than those in the NOAC trials. These sicker and more fragile patients might have a higher risk of bleeding, which is a potential reason for the NOAC underdosing. A current study has demonstrated that a substantial proportion of the NOAC underdosing may be voluntary, indicating a cautious approach to patients perceived to be at high risk of bleeding (27). The authors proposed that patients' characteristics (e.g., advanced age, previous bleedings, comorbidities), rather than the intensity of oral anticoagulant therapy, are associated with an increase in the bleeding risks (27).

In real-world settings, physicians are afraid of bleeding events induced by the anticoagulation treatment in patients with AF. As such, they tend to prescribe a reduced dose of NOACs with no indications. However, whether the NOAC underdosing could be the correct dosing for most of the NOAC users is unclear. Reduced dose regimens of NOACs might reduce the bleeding risk at a cost of the increased risk of AF-related thromboembolic events due to under exposure. A prior systematic review has concluded that AF patients treated with an off-label dose of NOACs did not acquire the full benefits of the anticoagulation treatment, and might increase the risks of stroke and bleeding events (6). However, this was only a descriptive analysis because limited quantitative data were linking NOAC-dose adjustments and adverse outcomes at that time. Given pooling of different data sources could improve the generalizability of research findings, we conducted a meta-analysis by including more studies to determine the effect of off-label underdose of NOACs in patients with AF. Our current evidence indicated that compared with the on-label dose of NOACs, the use of off-label underdose was associated with increased risks of SSE and allcause death. Of note, a case-control study by Paciaroni et al. (23) focused on a specific population (i.e., AF patients who had an acute cerebrovascular ischemic event); and the outcome was a recurrent stroke. Therefore, we performed a descriptive analysis for the study of Paciaroni et al. (23). In this study, off-label 


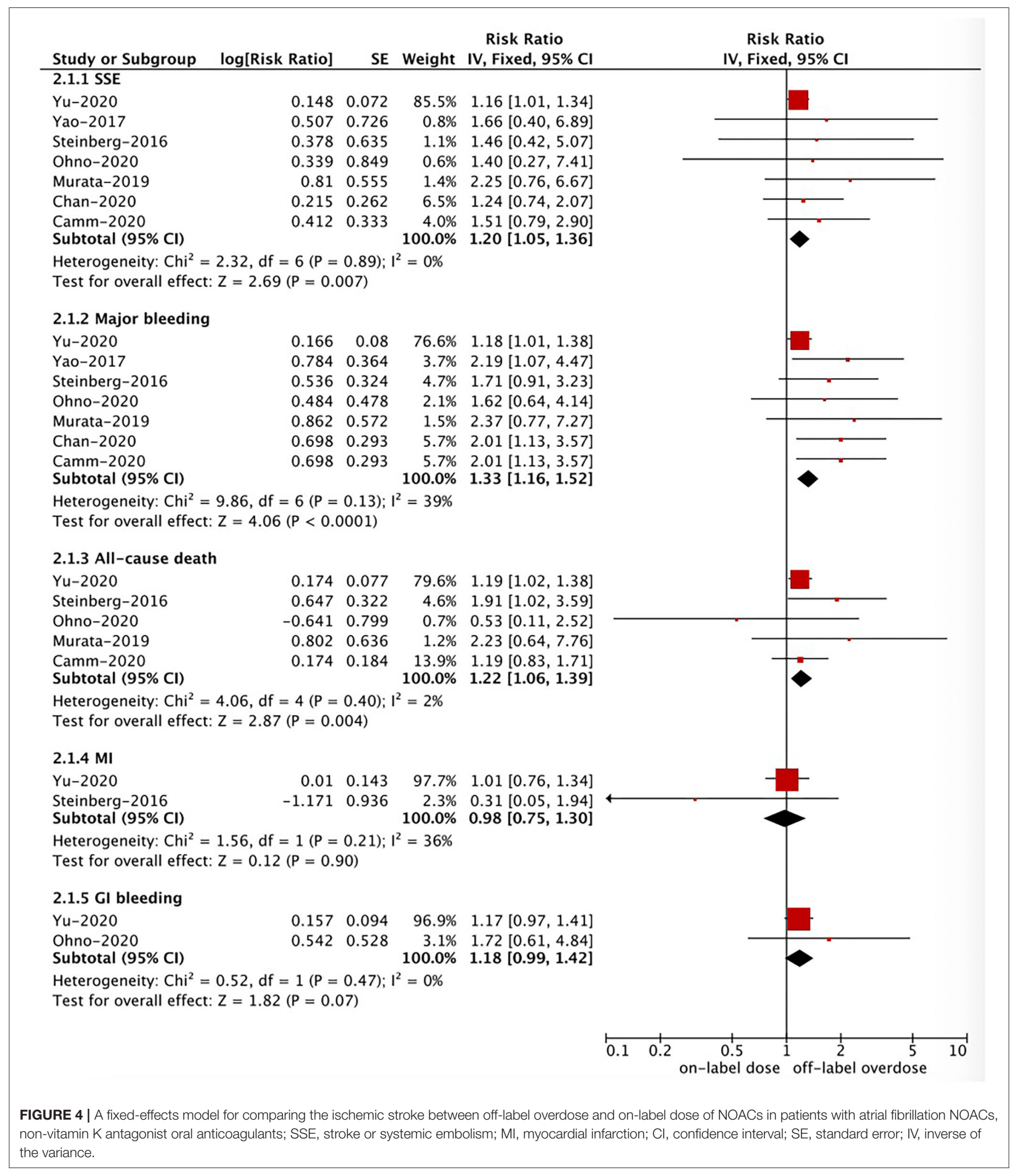

underdose of NOACs was associated with an increased risk of recurrent stroke $(\mathrm{RR}=3.18,95 \%$ CI 1.95-5.85). As such, it is important to have an appropriate NOAC dosing according to the label- or guideline- recommendations. Previous studies indicated that bleeding could be a problem in AF patients treated with the underdose of NOACs $(6,45,46)$. However, these studies 
did not account for differences in patient characteristics with adjustments. Our current meta-analysis only included the studies with adjusted data, suggesting that the incidence rate of major bleeding was similar between off-label underdose vs. on-label dose of NOACs. Inconsistent with the findings from the study of Bo et al., the use of off-label underdose of oral factor Xa inhibitors do not provide a sizeable net clinical benefit, but rather has increased risks of adverse events including hospitalizations for cardiovascular causes and stroke, without a reduced risk of bleeding (27).

In the study of Yao et al. (38) inappropriate reduced doses of apixaban reduced the effectiveness of stroke prevention, manifesting as a nearly 5-fold increased rate of stroke. Interestingly, the decreased effectiveness associated with an inappropriate reduced dose of apixaban was not found in AF patients treated with off-label underdose of dabigatran or rivaroxaban. Off-label underdose of rivaroxaban (34) increased the risk of IS, but dabigatran did not (39). Of note, the number of included studies in the subgroup analysis based on the type of NOACs was relatively small, which would limit the validity of the corresponding findings. Future prospective, dedicated, observational real-life studies should further shed some light on the potential clinical benefit of the off-label underdose of NOACs (considering the type of NOACs) in selected patients. In addition, further study would be improved if we could be more sure as to whether the underdosing of NOACs is due to overestimated bleeding risks, underestimated stroke risks, and patient's frailty. It is important to know why a practitioner might reasonably reduce the NOAC dosing. It is also important that not only the percentage dose reduction relative to theoretically ideal daily dosage be nominated, but also an increase in the inter-dose interval. Further clinical researches could pay close attention to these issues.

\section{Limitations}

Several limitations were noted in this meta-analysis. First, several unmeasured factors might exist in real-world studies, which

\section{REFERENCES}

1. January CT, Wann LS, Calkins H, Chen LY, Cigarroa JE, Cleveland JC, et al. 2019 AHA/ACC/HRS Focused Update of the 2014 AHA/ACC/HRS guideline for the management of patients with atrial fibrillation: a report of the American College of Cardiology/American Heart Association Task Force on clinical practice guidelines and the heart rhythm society in collaboration with the society of thoracic surgeons. Circulation. (2019). 140:R665. doi: 10.1161/CIR.0000000000000665

2. Zhu W, Ye Z, Chen S, Wu D, He J, Dong Y, et al. Comparative effectiveness and safety of non-vitamin $\mathrm{k}$ antagonist oral anticoagulants in atrial fibrillation patients. Stroke. (2021) 52:1225-33. doi: 10.1161/STROKEAHA.120.0 31007

3. Zhou Y, Ma J, Zhu W. Efficacy and safety of direct oral anticoagulants versus warfarin in patients with atrial fibrillation across bmi categories: a systematic review and meta-analysis. Am J Cardiovasc Drug. (2020) 20:5160. doi: 10.1007/s40256-019-00362-4

4. Chen C, Cao Y, Zheng Y, Dong Y, Ma J, Zhu W, et al. Effect of rivaroxaban or apixaban in atrial fibrillation patients with stage $4-5$ chronic could be the residual confounders. In addition, we only searched the PubMed database for relevant studies. Second, we did not perform the subgroup analysis based on the patient's age, sex and other information due to the limiting data. Third, information such as the adherence or persistence to NOACs were not considered.

\section{CONCLUSIONS}

Current evidence indicated that compared with the on-label dose of NOACs, the use of off-label underdose was associated with increased risks of SSE and all-cause death, whereas off-label overdose of NOACs was associated with increased risks of SSE, all-cause death, and major bleeding.

\section{DATA AVAILABILITY STATEMENT}

The original contributions generated for the study are included in the article/Supplementary Material, further inquiries can be directed to the corresponding authors.

\section{AUTHOR CONTRIBUTIONS}

All authors listed have made a substantial, direct and intellectual contribution to the work, and approved it for publication.

\section{ACKNOWLEDGMENTS}

The authors sincerely thank Dr. Wengen Zhu (Department of Cardiology, the First Affiliated Hospital of Sun Yat-Sen University, Guangzhou of Guangdong, China) for his directions in this meta-analysis.

\section{SUPPLEMENTARY MATERIAL}

The Supplementary Material for this article can be found online at: https://www.frontiersin.org/articles/10.3389/fcvm. 2021.724301/full\#supplementary-material

kidney disease or on dialysis. Cardiovasc Drug Ther. (2021) 35:27381. doi: 10.1007/s10557-021-07144-8

5. Kirchhof P, Benussi S, Kotecha D, Ahlsson A, Atar D, Casadei B, et al. (2016). ESC Guidelines for the management of atrial fibrillation developed in collaboration with EACTS. Eur Heart J. (2016) 37:2893962. doi: 10.5603/KP.2016.0172

6. Santos J, António N, Rocha M, Fortuna A. Impact of direct oral anticoagulantsoff-label doses on clinical outcomes of atrial fibrillation patients: a systematic review. Brit J Clin Pharmaco. (2019) 86:53347. doi: $10.1111 /$ bcp. 14127

7. Iguchi M, Akao M. Underdosing of direct oral anticoagulants- pros or cons? —. Circ J. (2019) 83:707-8. doi: 10.1253/circj.CJ-19-0069

8. Sato T, Aizawa Y, Fuse K, Fujita S, Ikeda Y, Kitazawa H, et al. The comparison of inappropriate-low-doses use among 4 direct oral anticoagulants in patients with atrial fibrillation: from the database of a single-center registry. J Stroke Cerebrovasc Dis. (2018) 27:32808. doi: 10.1016/j.jstrokecerebrovasdis.2018.07.028

9. Shimokawa H, Yamashita T, Uchiyama S, Kitazono T, Shimizu W, Ikeda T, et al. The EXPAND study: efficacy and safety of rivaroxaban in Japanese 
patients with non-valvular atrial fibrillation. Int J Cardiol. (2018) 258:12632. doi: 10.1016/j.ijcard.2018.01.141

10. Navarro-Almenzar B, Cerezo-Manchado JJ, Caro-Martinez C, GarcíaCandel F, Flores Blanco PJ, Ruiz GE, et al. Real-life behaviour of direct oral anticoagulants in a Spanish cohort with non-valvular atrial fibrillation: Refase Registry. Curr Med Res Opin. (2019) 35:2035-41. doi: 10.1080/03007995.2019.1647735

11. Inoue H, Uchiyama S, Atarashi H, Okumura K, Koretsune Y, Yasaka M, et al. Effectiveness and safety of long-term dabigatran among patients with non-valvular atrial fibrillation in clinical practice: J-dabigatran surveillance. $J$ Cardiol. (2019) 73:507-14. doi: 10.1016/j.jjcc.2018.12.013

12. Godino C, Bodega F, Melillo F, Rubino F, Parlati ALM, Cappelletti $A$, et al. Inappropriate dose of nonvitamin- $K$ antagonist oral anticoagulants: prevalence and impact on clinical outcome in patients with nonvalvular atrial fibrillation. J Cardiovasc Med. (2020) 21:751-8. doi: 10.2459/JCM.0000000000001043

13. Stoll S, Macha K, Marsch A, Gerner ST, Siedler G, Fröhlich K, et al. Ischemic stroke and dose adjustment of oral Factor Xa inhibitors in patients with atrial fibrillation. J Neurol. (2020) 267:2007-12. doi: 10.1007/s00415-020-09795-3

14. Inoue $H$, Umeyama $M$, Yamada $T$, Hashimoto $H$, Komoto $A$, Yasaka M. Safety and effectiveness of reduced-dose apixaban in Japanese patients with nonvalvular atrial fibrillation in clinical practice: a sub-analysis of the STANDARD study. J Cardiol. (2020) 75:208-15. doi: 10.1016/j.jjcc.2019.07.007

15. Atarashi H, Uchiyama S, Inoue H, Kitazono T, Yamashita T, Shimizu W, et al. Ischemic stroke, hemorrhage, and mortality in patients with nonvalvular atrial fibrillation and renal dysfunction treated with rivaroxaban: sub-analysis of the EXPAND study. Heart Vessels. (2021) 36:141020. doi: 10.1007/s00380-021-01810-5

16. Steinberg BA, Shrader P, Pieper K, Thomas L, Allen LA, Ansell J, et al. Frequency and outcomes of reduced dose non-vitamin $\mathrm{k}$ antagonist anticoagulants: results from ORBIT-AF II (The Outcomes Registry for Better Informed Treatment of Atrial Fibrillation II). J Am Heart Assoc. (2018) 7:7633. doi: 10.1161/JAHA.117.007633

17. Lee SR, Choi EK, Han KD, Jung JH, Oh S, Lip G. Optimal rivaroxaban dose in asian patients with atrial fibrillation and normal or mildly impaired renal function. Stroke. (2019) 50:1140-8. doi: 10.1161/STROKEAHA.118.024210

18. Kobayashi T, Sotomi Y, Hirata A, Sakata Y, Hirayama A, Higuchi Y. Impact of direct oral anticoagulant off-label reduced dose in combination with antiplatelet agents on clinical outcome- propensity score-matching analysis from the DIRECT Real-world non-valvular atrial fibrillation registry. Circ Rep. (2020) 2:289-96. doi: 10.1253/circrep.CR-20-0026

19. Salameh M, Gronich N, Stein N, Kotler A, Rennert G, Auriel E, et al. Stroke and bleeding risks in patients with atrial fibrillation treated with reduced apixaban dose: a real-life study. Clin Pharmacol Ther. (2020) 108:126573. doi: 10.1002/cpt.1952

20. Lee S, Choi E, Park S, Jung J, Han K, Oh S, et al. Off-label underdosed apixaban use in Asian patients with non-valvular atrial fibrillation. Eur Heart J. (2021). doi: 10.1093/ehjcvp/pvab004. [Epub ahead of print].

21. Miyazaki M, Matsuo K, Uchiyama M, Nakamura Y, Sakamoto Y, Misaki $\mathrm{M}$, et al. Inappropriate direct oral anticoagulant dosing in atrial fibrillation patients is associated with prescriptions for outpatients rather than inpatients: a single-center retrospective cohort study. J Pharm Health Care Sciences. (2020) 6:2. doi: 10.1186/s40780-020-0157-z

22. Amarenco P, Haas S, Hess S, Kirchhof P, Lambelet M, Bach M, et al. Outcomes associated with non-recommended dosing of rivaroxaban: results from the XANTUS study. Eur Heart J. (2019) 5:70-9. doi: 10.1093/ehjcvp/pvy041

23. Paciaroni M, Agnelli G, Caso V, Silvestrelli G, Seiffge DJ, Engelter $S$, et al. Causes and risk factors of cerebral ischemic events in patients with atrial fibrillation treated with non-vitamin $\mathrm{k}$ antagonist oral anticoagulants for stroke prevention. Stroke. (2019) 50:2168-74. doi: 10.1161/STROKEAHA.119.025350

24. Anouassi Z, Atallah B, Alsoud LO, El NW, Al MW, AlJaabari $\mathrm{M}$, et al. Appropriateness of the direct oral anticoagulants dosing in the middle east gulf region. J Cardiovasc Pharmacol. (2021) 77:182-8. doi: 10.1097/FJC.0000000000000913

25. Raccah PPB, Erlichman Y, Pollak A, Matok I, Muszkat M. Prescribing errors with direct oral anticoagulants and their impact on the risk of bleeding in patients with atrial fibrillation. J Cardiovasc Pharmacol Ther. (2021). doi: 10.1177/10742484211019657. [Epub ahead of print].

26. Fernandez MS, Marin F, Rafols C, Arribas F, Barrios V, Cosin-Sales J, et al. Thromboembolic and bleeding events with rivaroxaban in clinical practice in Spain: impact of inappropriate doses (the EMIR study). J Comp Eff Res. (2021) 10:583-93. doi: 10.2217/cer-2020-0286

27. Chen I, Chang W, Hsu P, Yeh Y, Zheng S, Huang Y, et al. Offlabel reduced-dose apixaban does not reduce hemorrhagic risk in Taiwanese patients with nonvalvular atrial fibrillation. Medicine. (2021) 100:e26272. doi: 10.1097/MD.0000000000026272

28. Ashraf H, Agasthi P, Shanbhag A, Mehta RA, Rattanawong P, Allam M, et al. Long-term clinical outcomes of underdosed direct oral anticoagulants in patients with atrial fibrillation and atrial flutter. Am J Med. (2021) 134:788796. doi: 10.1016/j.amjmed.2020.12.022

29. Ohno J, Sotomi Y, Hirata A, Sakata Y, Hirayama A, Higuchi Y. Dose of direct oral anticoagulants and adverse outcomes in Asia. Am J Cardiol. (2021) 139:50-6. doi: 10.1016/j.amjcard.2020.09.053

30. Yu HT, Yang PS, Jang E, Kim TH, Uhm JS, Kim JY, et al. Label adherence of direct oral anticoagulants dosing and clinical outcomes in patients with atrial fibrillation. J Am Heart Assoc. (2020) 9:14177. doi: 10.1161/JAHA.119.0 14177

31. Chan Y, Chao T, Chen S, Lee H, Yeh Y, Huang Y, et al. Off-label dosing of non-vitamin $\mathrm{k}$ antagonist oral anticoagulants and clinical outcomes in asian patients with atrial fibrillation. Heart Rhythm. (2020) 17:210210. doi: $10.1016 /$ j.hrthm.2020.07.022

32. Camm AJ, Cools F, Virdone S, Bassand J, Fitzmaurice DA, Arthur Fox KA, et al. Mortality in patients with atrial fibrillation receiving nonrecommended doses of direct oral anticoagulants. J Am Coll Cardiol. (2020) 76:142536. doi: 10.1016/j.jacc.2020.07.045

33. Briasoulis A, Gao Y, Inampudi C, Alvarez P, Asleh R, Chrischilles E, et al. Characteristics and outcomes in patients with atrial fibrillation receiving direct oral anticoagulants in off-label doses. BMC Cardiovasc Disor. (2020) 20:42. doi: $10.1186 / \mathrm{s} 12872-020-01340-4$

34. Cheng W, Chao T, Lin Y, Chang S, Lo L, Hu Y, et al. Low-dose rivaroxaban and risks of adverse events in patients with atrial fibrillation. Stroke. (2019) 50:2574-7. doi: 10.1161/STROKEAHA.119.025623

35. Ikeda T, Ogawa S, Kitazono T, Nakagawara J, Minematsu K, Miyamoto S, et al. Outcomes associated with under-dosing of rivaroxaban for management of non-valvular atrial fibrillation in real-world Japanese clinical settings. $J$ Thromb Thrombolys. (2019) 48:653-60. doi: 10.1007/s11239-019-01934-6

36. Murata N, Okumura Y, Yokoyama K, Matsumoto N, Tachibana E, Kuronuma $\mathrm{K}$, et al. Clinical Outcomes of off-label dosing of direct oral anticoagulant therapy among Japanese patients with atrial fibrillation identified from the SAKURA AF Registry. Circ J. (2019) 83:727-35. doi: 10.1253/circj.CJ-18-0991

37. Arbel R, Sergienko R, Hammerman A, Greenberg-Dotan S, Batat E, Avnery $\mathrm{O}$, et al. Effectiveness and safety of off-label dose-reduced direct oral anticoagulants in atrial fibrillation. Am J Med. (2019) 132:84755. doi: 10.1016/j.amjmed.2019.01.025

38. Yao X, Shah ND, Sangaralingham LR, Gersh BJ, Noseworthy PA. Nonvitamin $\mathrm{k}$ antagonist oral anticoagulant dosing in patients with atrial fibrillation and renal dysfunction. J Am Coll Cardiol. (2017) 69:277990. doi: 10.1016/j.jacc.2017.03.600

39. Lee KH, Park HW, Lee N, Hyun DY, Won J, Oh SS, et al. Optimal dose of dabigatran for the prevention of thromboembolism with minimal bleeding risk in Korean patients with atrial fibrillation. Europace. (2017) 19:v19. doi: 10.1093/europace/eux247

40. Steinberg BA, Shrader P, Thomas L, Ansell J, Fonarow GC, Gersh BJ, et al. Off-label dosing of non-vitamin $\mathrm{k}$ antagonist oral anticoagulants and adverse outcomes. J Am Coll Cardiol. (2016) 68:2597-604. doi: 10.1016/j.jacc.2016.09.966

41. Liu X, Huang M, Ye C, Xiao X, Yan C. Effect of non-recommended doses versus recommended doses of direct oral anticoagulants in atrial fibrillation patients: a meta-analysis. Clin Cardiol. (2021) 44:472-80. doi: $10.1002 /$ clc.23586

42. Shen NN, Zhang C, Hang Y, Li Z, Kong LC, Wang N, et al. Realworld prevalence of direct oral anticoagulant off-label doses in atrial fibrillation: an epidemiological meta-analysis. Front Pharmacol. (2021) 12:581293. doi: 10.3389/fphar.2021.581293 
43. Ito M, Kaikita K, Sueta D, Ishii M, Oimatsu Y, Mitsuse T, et al. Inappropriate dose of direct oral anticoagulants therapy in patients with non-valvular atrial fibrillation. Eur heart J. (2018) 39:485-6. doi: 10.1093/eurheartj/ehy565. P2504

44. Steinberg BA, Holmes DN, Piccini JP, Ansell J, Chang P, Fonarow GC, et al. Early adoption of dabigatran and its dosing in US patients with atrial fibrillation: results from the outcomes registry for better informed treatment of atrial fibrillation. J Am Heart Assoc. (2013) 2:e535. doi: 10.1161/JAHA.113.000535

45. Schafer JH, Casey AL, Dupre KA, Staubes BA. Effectiveness and safety of apixaban versus warfarin in patients with advanced chronic kidney disease. Ann Pharmacother. (2018) 52:1078-84. doi: 10.1177/10600280187 81853

46. Eisho S, Salem NM, Hoffman JL, Koerber JM, Smythe MA. Major bleeding with apixaban in atrial fibrillation: patient characteristics, management, and outcomes. Hosp Pract. (1995). (2018) 46:165-9. doi: $10.1080 / 21548331.2018 .1506675$
Conflict of Interest: The authors declare that the research was conducted in the absence of any commercial or financial relationships that could be construed as a potential conflict of interest.

Publisher's Note: All claims expressed in this article are solely those of the authors and do not necessarily represent those of their affiliated organizations, or those of the publisher, the editors and the reviewers. Any product that may be evaluated in this article, or claim that may be made by its manufacturer, is not guaranteed or endorsed by the publisher.

Copyright $\odot 2021 \mathrm{Wu}, \mathrm{Hu}$, Liu and $\mathrm{Gu}$. This is an open-access article distributed under the terms of the Creative Commons Attribution License (CC BY). The use, distribution or reproduction in other forums is permitted, provided the original author(s) and the copyright owner(s) are credited and that the original publication in this journal is cited, in accordance with accepted academic practice. No use, distribution or reproduction is permitted which does not comply with these terms. 